\title{
Trends and correlates of maternal, newborn and child health services utilization in primary healthcare facilities: an explorative ecological study using DHIMSII data from one district in the Volta region of Ghana
}

Robert Kaba Alhassan ${ }^{1 *}$ (D), Seth Owusu-Agyei ${ }^{1}$, Evelyn Korkor Ansah ${ }^{1}$, Margaret Gyapong ${ }^{1}$, Anthony Ashinyo ${ }^{2}$, Mary Eyram Ashinyo ${ }^{3}$, Edward Nketiah-Amponsah ${ }^{4}$,Edem Akorli-Adzimah ${ }^{5}$ and Edith Ekpor ${ }^{5}$

\footnotetext{
Abstract

Background: Sustainable Development Goal 3 aims at reducing global neonatal mortality to at least 12 per 1000 livebirths, under-five mortality to at least 25 per 1000 livebirths and maternal mortality ratio to less than 70 per 100, 000 livebirths by 2030. Considering the achievement so far, many countries in sub-Saharan Africa, including Ghana are not likely to achieve these targets. Low utilization of maternal, newborn and child health (MNCH) services partly account for this predicament. This study explored the trend and correlates of MNCH services utilization in one administrative district in the Volta Region of Ghana.

Methods: This is an explorative ecological study employing trend analysis of 2015-2017 data from Ghana Health Service District Health Information Management System II. Univariate Poisson regression models were used to determine the factors associated with MNCH services utilization at 95\% confidence level.

Results: Cumulative record of 17,052 antenatal care (ANC) attendance and 2162 facility-based spontaneous vaginal deliveries (SVDs) was discovered. Compelling evidence of potential unskilled deliveries was observed in $23 \%$ of the 26 facilities reported in the DHIMSII data. High cumulative number of midwives in health facilities associated positively with high records of ANC visits (IRR $=1.30,[95 \% \mathrm{Cl}: 1.29,1.32] ; p=0.0001)$, facility-based SVDs (IRR $=1.30$ [95\% Cl:1.25, 1.35]; $p=0.0001$ ) and BCG immunizations (IRR = 1.32 [95\% Cl:1.29, 1.34]; $p=0.0001)$. Likewise, high records of ANC visits correlated positively with high facility-based SVDs and child immunizations records $(p<$ 0.0001).

\footnotetext{
*Correspondence: ralhassan@uhas.edu.gh; arkabason@gmail.com

${ }^{1}$ Institute of Health Research, University of Health and Allied Sciences, Ho, Ghana

Full list of author information is available at the end of the article
}

(c) The Author(s). 2020 Open Access This article is licensed under a Creative Commons Attribution 4.0 International License, which permits use, sharing, adaptation, distribution and reproduction in any medium or format, as long as you give appropriate credit to the original author(s) and the source, provide a link to the Creative Commons licence, and indicate if changes were made. The images or other third party material in this article are included in the article's Creative Commons licence, unless indicated otherwise in a credit line to the material. If material is not included in the article's Creative Commons licence and your intended use is not permitted by statutory regulation or exceeds the permitted use, you will need to obtain permission directly from the copyright holder. To view a copy of this licence, visit http://creativecommons.org/licenses/by/4.0/ The Creative Commons Public Domain Dedication waiver (http://creativecommons.org/publicdomain/zero/1.0/) applies to the data made available in this article, unless otherwise stated in a credit line to the data. 
(Continued from previous page)

Conclusion: Targeted health system and community level interventions alongside progressive frontline health staff motivation and retention strategies could further enhance enrollment and retention of mothers in pre-natal and postnatal care services throughout the continuum of care to guarantee better MNCH health outcomes. Investments in universal coverage for quality ANC services has the potential to enhance utilization of supervised deliveries and post-natal care services such as immunizations.

Keywords: Continuum of care, District health information management system II, Facility-based spontaneous vaginal deliveries, Maternal, Newborn and child health, Child immunizations, Utilization, Primary healthcare, Antenatal care, Health policy, Ghana

\section{Background}

Maternal, newborn and child health $(\mathrm{MNCH})$ are important indicators of health systems' performance across the globe [1]. Sustainable Development Goal (SDG) 3 aims at reducing global neonatal mortality to at least 12 per 1000 livebirths, under-five mortality to at least 25 per 1000 livebirths and maternal mortality ratio to less than 70 per 100,000 livebirths by 2030 [1]. Unfortunately, many countries in sub-Saharan Africa, including Ghana, are not likely to achieve these targets before the end of 2030 [2, 3].

In 2016, maternal mortality ratio (MMR) in the WHO African Region was estimated to be 542 per 100,000 livebirths compared to 16 per 100,000 in Europe. MMR in sub-Saharan Africa is projected to improve marginally to 347 per 100,000 by 2030 which is 34 times higher than the average MMR ratio in Europe [2]. The current pace of decline in maternal mortality in Africa suggests that the continent will not attain the MMR target of 70 per 100,000 livebirths until 2084 [2].

Additionally, the proportion of facility-based deliveries and births attended to by skilled health personnel in Africa remains lowest in the world, recording an average rate of 59\% between 2013 and 2018 compared to 99\% in Europe, 97\% in Western Pacific, 95\% in the Americas, $81 \%$ in SouthEast Asia and 79\% in Eastern Mediterranean region [2].

Ghana continues to experience unacceptable levels of maternal, neonatal and child mortalities coupled with low immunization coverage for vaccine preventable childhood diseases. Per Ghana's current neonatal mortality of 29 per 1000 livebirths, it is not likely the 2030 target of 12 per 1000 live births will be met [4]. Similarly, the WHO target of 70 per 100,000 by the year 2030 will be missed if there are no improvements in maternal, newborn and child health (MNCH) services [2]. As at 2016, the proportion of pregnant women who had skilled supervised deliveries was $71 \%$, far below the SDG target of $90 \%$, even though better than the African average of 54\% [2].

Immunization coverage for Diphtheria Pertussis Tetanus (DPT) or Pentavalent3 (Penta3) in Ghana in 2016 was $93 \%$ with Penta1 coverage of $94 \%$ [2]. The proportion of children aged $<1$ year who received up to three doses of polio3 vaccine was $95 \%$ in 2016 above the African average of 73\%; likewise, coverage of Bacillus Calmette Guerin (BCG) and measles vaccine were 94 and $89 \%$ respectively compared to the WHO African region averages of 81 and $72 \%$ respectively [2].

Notwithstanding the progressive efforts towards increasing accessibility and utilization of $\mathrm{MNCH}$ services in Ghana, there are rural-urban gaps in access to basic healthcare services throughout the continuum of care $(\mathrm{CoC})$ for $\mathrm{MNCH}$ services. Volta Region is one of the relatively under-resourced regions in Ghana in terms of health infrastructure with undesirable health outcome indicators. As per the Expanded Programme on Immunization (EPI) schedule in Ghana (see Table 1), the Volta region is among the worst performing regions in the country. In 2018, the region recorded the lowest measles immunization coverage of $80.7 \%$, below the national average of $92.4 \%$ [4].

Similarly, Penta3 (DPT3) immunization coverage in the Volta Region in 2018 was $86.3 \%$, below the national average of $97.3 \%$. The region performed below the national average in Oral Polio Vaccine 3 (OPV3) and BCG immunization coverage [4] and recorded the lowest ANC coverage of $68.8 \%$ in 2016 while the percentage of supervised deliveries was $43.7 \%$ compared to the national average of $56.2 \%$ [4].

In terms of health sector human resources, the doctor to patient ratio in the Volta Region in 2018 was 1: 11, 857 compared to the national average of 1: 7058. Nurse: patient ratio was estimated to be $1: 567$, relative to the national average of 1: 508 [4] and midwife to WIFA population ratio was 1: 728 compared to the national average of $1: 677$ [4].

This paper explored the trends and correlates of $\mathrm{MNCH}$ services utilization throughout the continuum of care $(\mathrm{CoC})$ in 26 primary healthcare facilities in Ho West District (HWD) of the Volta Region of Ghana.

\section{Methods}

\section{Study design}

The study is an explorative ecological design using secondary data from the Ghana Health Service (GHS) 
Table 1 Expanded Programme on Immunization (EPI) schedules in Ghana

\begin{tabular}{|c|c|c|c|c|c|}
\hline Num. & Vaccine & Age & Dose & Route/site of administration & Disease(s) \\
\hline 1 & $\mathrm{BCG}$ & At birth & $0.05 \mathrm{ml}$ & Intradermal right upper arm & Tetanus \\
\hline 2 & OPVO & At birth & 2drops & Oral & Poliomyelitis \\
\hline 1 & DPT-HepB-Hib1 & 6 weeks & $0.5 \mathrm{ml}$ & IM, lateral part of left thigh & $\begin{array}{l}\text { Diphtheria, pertussis, Tetanus, Hepatitis B } \\
\text { and Haemophilus Influenza type B }\end{array}$ \\
\hline 2 & OPV1 & 6 weeks & 2drops & Oral & Poliomyelitis \\
\hline 3 & Pneumo 1 & 6 weeks & $0.5 \mathrm{ml}$ & IM, lateral part of right thigh & Pneumococcal diseases (pneumonia) \\
\hline 4 & Rota 1 & 6 weeks & $1.5 \mathrm{ml}$ vial & Oral & Diarrhoea \\
\hline 1 & OPV2 & 10 weeks & 2drops & Oral & Poliomyelitis \\
\hline 2 & DPT-HepB-Hib2 & 10 weeks & $0.5 \mathrm{ml}$ & IM, lateral part of left thigh & $\begin{array}{l}\text { Diphtheria, pertussis, Tetanus, Hepatitis B } \\
\text { and Haemophilus Influenza type B }\end{array}$ \\
\hline 3 & Pneumo 2 & 10 weeks & $0.5 \mathrm{ml}$ & IM, lateral part of right thigh & Pneumococcal diseases (pneumonia) \\
\hline 4 & Rota 2 & 10 weeks & $1.5 \mathrm{ml} \mathrm{vial}$ & Oral & Diarrhoea \\
\hline 1 & OPV3 & 14 weeks & 2drops & Oral & Poliomyelitis \\
\hline 2 & DPT-HepB-Hib3 & 14 weeks & $0.5 \mathrm{ml}$ & IM, lateral part of left thigh & $\begin{array}{l}\text { Diphtheria, pertussis, Tetanus, Hepatitis B and } \\
\text { Haemophilus Influenza type B }\end{array}$ \\
\hline 3 & Pneumo 3 & 14 weeks & $0.5 \mathrm{ml}$ & IM, lateral part of right thigh & Pneumococcal diseases (pneumonia) \\
\hline 4 & Rota 3 & 14 weeks & $1.5 \mathrm{ml}$ vial & Oral & Diarrhoea \\
\hline 1 & Vitamin A & 6 months & $100,000 \mathrm{IU}$ & Oral & Diet supplementation \\
\hline 2 & Measles-Rubella & 9 months & $0.5 \mathrm{ml}$ & Subcutaneous, left upper arm & Measles, Rubella \\
\hline 3 & Yellow fever & 9 months & $0.5 \mathrm{ml}$ & Subcutaneous, right upper arm & Yellow fever \\
\hline 1 & Vitamin A & 12 months & $200,000 \mathrm{IU}$ & Oral & Diet supplementation \\
\hline 1 & Measles & 18 months & $0.5 \mathrm{ml}$ & Subcutaneous, left upper arm & Measles \\
\hline 2 & Vitamin A & 18 months & $200,000 \mathrm{IU}$ & Oral & Diet supplementation \\
\hline
\end{tabular}

Source: Ghana Health Service/Ministry of Health Expanded Programme on Immunization (2020)

Note: After 18 months, Vitamin A is given every 6 months until the child is 5 years old

At 18 months, LLINs Long lasting Insecticide Treated Nets is given to the child

District Health Information Management System II (DHIMSII), 2015-2017. The DHIMSII data comprises of 26 primary healthcare facilities (i.e. clinics, health centres and functional community-based health planning and services (CHPS)) located in urban and rural communities in the HDW. These facilities comprised of both private and public facilities.

Functional CHPS compounds are the basic unit of Ghana's health service delivery system where there is usually a trained resident Community Health Officer $(\mathrm{CHO})$ (i.e. community health nurse, midwife or general nurse). Functional CHPS compounds turn to render more health services including $\mathrm{MNCH}$ services than the CHPS zones which are often coterminous with electoral areas within districts. In this paper, the use of CHPS compounds mainly connotes functional CHPS compounds excluding CHPS zones.

\section{Study setting, population and data sources}

Data used for analyses was mainly from HWD, one of the 25 administrative districts in the Volta Region. Volta Region has a population of 2,118,252 (48\% males and $52 \%$ females), representing approximately $7 \%$ of the estimated 30,380,482 million people in Ghana (cited in GHS, [4]). The region has 732 healthcare facilities comprising of one (1) teaching hospital, 30 hospitals, 45 clinics, 156 health centres, 14 maternity homes, 4 polyclinics and 482 CHPS compounds. HWD has an estimated population of 94,600 , representing $5 \%$ the regional population [4].

The DHIMSII ecological data comprised mainly of primary healthcare facilities that render spontaneous vaginal deliveries (SVDs), antenatal care (ANC), postnatal care (PNC) and child immunizations services. The Ghana Health Service (GHS) pyramidal levels of care classify clinics, polyclinics, health centres and functional CHPS compounds as primary healthcare facilities with a mandate to manage minor and uncomplicated medical conditions. Conditions from this level of care are referred to district and regional hospitals, which in turn refer complicated cases to tertiary facilities such as the teaching hospitals. At the time of conducting this study, the total number of primary health care facilities in the HWD were 27, but 26 of these had complete information in DHIMSII from 2015 to 2017 (see Supplementary File_1). 


\section{Sampling procedure}

Employing the census technique, data from all eligible primary healthcare facilities $(N=26)$ in the HWD district was retrieved from DHIMSII, cleaned and analyzed. Data from the DHIMSII is reported cumulatively from all facilities within the district. In view of this, the unit of analysis was the health facilities with pooled data (not individual patient level) to avoid committing an ecological fallacy. The DHIMSII data was analyzed using cumulative number of SVDs, ANC attendance and immunizations for BCG, OPV1, OPV3, Penta-1, Penta-3, Yellow Fever and Measles from 2015 to 2017. Background information on facility ownership, level of care, location, catchment population of women in fertile age (WIFA), number of midwives and other cadre of frontline health staff was extracted and analyzed. Only health facilities under the jurisdiction/supervision of Ho West District Health Management Team (DHMT) were considered eligible for inclusion into this study.

\section{Data extraction and analysis}

Data on $\mathrm{MNCH}$ service indicators was retrieved from DHIMS II with the assistance of the district health information officer using an extraction form developed by the researchers. Data validation was carried out by the District Director of Health of HWD at the time of the study. Extracted DHIMSII data was cleaned and coded in Microsoft Excel and later exported to STATA statistical analysis software (version 12.0) for analysis. Facility names were anonymized with codes to maintain privacy and confidentiality. Summary statistics were generated and test for differences between groups was done using the independent $\mathrm{t}$-test. Univariate Poisson regression models were employed to predict determinants of utilization of $\mathrm{MNCH}$ services.

Missing data was handled mainly through deletion since the data set was an ecological/cluster secondary data that did not make room for imputation as part of the missing data management process. Thus, prior to the final analysis, listwise deletion was done for missing observations (i.e. one out of the 27 health facilities without DHIMSII required data). Additionally, column (variable) deletion was done for missing variables.

\section{Outcome variables for Poisson regression models}

Poisson regression was employed to predict the main outcome variables of interest since the latter are all count variables with non-negative values. Likewise, the outcome variables are not over-dispersed and do not have excessive number of zeros [5]. The outcome variables of interest were the pooled facility-based number of SVDs, number of ANC visits and child immunizations (BCGs, OPV1, OPV3, Penta-1, Penta-3, Yellow Fever and Measles immunization). Some of the immunization schedules were not recorded in the DHIMSII hence were not included in the analysis.

Incidence Rate Ratio (IRR) was used as the output reporting option in place of the default coefficients. IRRs are transformed estimated coefficients, standard errors and confidence intervals [5] and since they only affect how results are displayed and not how they are estimated or stored, they were deemed appropriate. The exposure option was not accounted for in the Poisson regression models, without risking estimation bias, because all observations in the pooled dataset had the same and consistent data reporting from 2015 to 2017.

Even though count variables are sometimes logtransformed and analyzed using Ordinary Least Squares (OLS) regression, this statistical test was not considered on this occassion because of its peculiar limitations in count data estimations [5]. Use of OLS in count data could result in loss of data due to generation of undefined values which has the propensity of producing biased estimates [6].

\section{Covariates of the Poisson regression models}

Independent variables loaded in the Poisson regression models were: facility ownership, location, number of midwives per health facility, number of other health staff per health facility, WIFA population and number of ANC visits in a health facility per year. Multicollinearity diagnostics were conducted on all explanatory variables before fitting them into the regression models and those with variance inflation factors (VIFs) more than the 10.0 rule of thumb [6] were dropped. "Facility ownership" was therefore dropped for recording VIF above 10.0. Statistical significance was set at $95 \%$ for all analysis.

\section{Results}

Situational analysis of health facilities

Out of the population of 27 eligible health facilities, 26 of the them were included, because they had the required complete DHIMSII data, resulting in data completeness rate of $96 \%$. Situational analysis of the health facilities showed that 2 out of the 26 facilities (8\%) were urban with the remaining (92\%) being rural. Likewise, 2 out of the 26 facilities (2\%) were privately owned with the bulk 24 (92\%) being publicly owned. In terms of the level of care, Tables 2 \& 3 show that health centres dominated with $46 \%(12 / 26)$ followed by CHPS compounds $39 \%(10 / 26)$ and then clinics $15 \%(4 / 26)$. Cumulative number of BCGs recorded in all the 26 facilities from 2015 to 2017 was 10,787 as per the DHIMSII data; records of subsequent immunizations given from 6 weeks in the continuum of care $(\mathrm{CoC})$ were comparatively higher, as shown in Table 3. 
Table 2 Absolute cumulative maternal health service utilization per facility and corresponding staff population (2015-2017)

\begin{tabular}{|c|c|c|c|c|c|c|c|c|c|}
\hline SN & Location & Ownership & Level & $\begin{array}{l}\text { SVDs } \\
(\mathrm{N})\end{array}$ & $\begin{array}{l}\text { ANC Attendance } \\
(\mathrm{N})\end{array}$ & $\begin{array}{l}\text { SVDs per } \\
\text { midwife }^{a}\end{array}$ & $\begin{array}{l}\text { WIFA population } \\
(\mathrm{N})\end{array}$ & $\begin{array}{l}\text { Midwives per clinic } \\
(\mathrm{N})\end{array}$ & $\begin{array}{l}\text { Other staff per } \\
\text { clinic }(\mathrm{N})\end{array}$ \\
\hline 1 & Rural & Public & Clinic & 0 & 0 & 0 & 0 & 0 & 3 \\
\hline 2 & Rural & Private & Clinic & 221 & 513 & 74 & 0 & 3 & 6 \\
\hline 3 & Rural & Public & $\begin{array}{l}\text { CHPS } \\
\text { Compound }\end{array}$ & 7 & 199 & 0 & 704 & 0 & 3 \\
\hline 4 & Rural & Public & Health Centre & 42 & 369 & 21 & 1161 & 2 & 9 \\
\hline 5 & Rural & Public & Health Centre & 148 & 1240 & 49 & 1175 & 3 & 12 \\
\hline 6 & Rural & Public & Health Centre & 191 & 1350 & 64 & 1227 & 3 & 12 \\
\hline 7 & Rural & Public & Health Centre & 13 & 160 & 7 & 1428 & 2 & 6 \\
\hline 8 & Rural & Public & $\begin{array}{l}\text { CHPS } \\
\text { Compound }\end{array}$ & 0 & 93 & 0 & 1839 & 0 & 6 \\
\hline 9 & Rural & Public & Health Centre & 38 & 389 & 19 & 2134 & 2 & 6 \\
\hline 10 & Rural & Public & Health Centre & 7 & 145 & 0 & 2323 & 0 & 6 \\
\hline 11 & Rural & Public & $\begin{array}{l}\text { CHPS } \\
\text { Compound }\end{array}$ & 20 & 304 & 10 & 2706 & 2 & 6 \\
\hline 12 & Rural & Public & $\begin{array}{l}\text { CHPS } \\
\text { Compound }\end{array}$ & 271 & 617 & 136 & 2828 & 2 & 6 \\
\hline 13 & Rural & Public & $\begin{array}{l}\text { CHPS } \\
\text { Compound }\end{array}$ & 47 & 606 & 0 & 2955 & 0 & 6 \\
\hline 14 & Rural & Public & $\begin{array}{l}\text { CHPS } \\
\text { Compound }\end{array}$ & 30 & 339 & 0 & 3087 & 0 & 6 \\
\hline 15 & Rural & Public & Health Centre & 219 & 1550 & 110 & 3108 & 2 & 21 \\
\hline 16 & Rural & Public & Health Centre & 83 & 353 & 42 & 3293 & 2 & 15 \\
\hline 17 & Rural & Public & $\begin{array}{l}\text { CHPS } \\
\text { Compound }\end{array}$ & 13 & 179 & 0 & 3471 & 0 & 6 \\
\hline 18 & Rural & Public & $\begin{array}{l}\text { CHPS } \\
\text { Compound }\end{array}$ & 0 & 290 & 0 & 3604 & 0 & 6 \\
\hline 19 & Rural & Public & Health Centre & 34 & 451 & 34 & 3654 & 1 & 9 \\
\hline 20 & Rural & Public & Health Centre & 108 & 749 & 36 & 3848 & 3 & 21 \\
\hline 21 & Rural & Public & Health Centre & 39 & 474 & 20 & 3989 & 2 & 24 \\
\hline 22 & Rural & Public & $\begin{array}{l}\text { CHPS } \\
\text { Compound }\end{array}$ & 3 & 237 & 0 & 4729 & 0 & 6 \\
\hline 23 & Rural & Public & $\begin{array}{l}\text { CHPS } \\
\text { Compound }\end{array}$ & 0 & 525 & 0 & 5411 & 0 & 6 \\
\hline 24 & Urban & Public & Clinic & 445 & 3539 & 37 & 6302 & 12 & 0 \\
\hline 25 & Urban & Public & Health Centre & 183 & 2151 & 46 & 13,931 & 4 & 38 \\
\hline 26 & Rural & Private & Clinic & 0 & 230 & 0 & 78,906 & 3 & 21 \\
\hline \multicolumn{4}{|c|}{ Total } & 2162 & 17,052 & 45 & 157,811 & 48 & 13 \\
\hline
\end{tabular}

Source: GHS/DHIMS II (Ho West District, 2015-2017)

Legend: ANC (Antenatal Care); SVDs (Spontaneous Vaginal Deliveries); WIFA (Women in Fertility Age); CHPS (Community-based Health Planning and Services); N

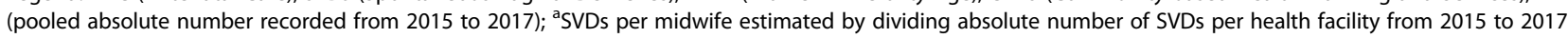
over the absolute number of midwives in the pertinent health facility over the same time period (2015-2017)

For staff capacity, it was found that 48 midwives and 13 other cadre of health staff were recorded in the 26 facilities between 2015 and 2017; the 48 midwives served a total WIFA population of 157, 811, representing midwife: WIFA population ratio of 1 : 3 , 288 over the period. As shown in Table 2, the number of midwives per health facility ranged from none to highest of 12 .
Trend of maternal, newborn and child health (MNCH) services utilization

Data from the DHIMSII show that a cumulative number of 2162 facility-based SVDs were recorded by 21 facilities between 2015 and 2017. Five (5) of the facilities did not have a record on facility-based SVD within the three-year period (2015-2017) in the DHIMSII; the highest cumulative facility-based SVDs over the 3 years 
Table 3 Absolute cumulative child immunizations per health facility (2015-2017)

\begin{tabular}{|c|c|c|c|c|c|c|c|c|c|c|}
\hline SN. & Level & Location & Ownership & BCG & OPV1 & OPV3 & Penta 1 & Penta 3 & Yellow Fever & Measles \\
\hline 1 & Clinic & Rural & Public & 0 & 0 & 0 & 0 & 0 & 0 & 0 \\
\hline 2 & Clinic & Rural & Private & 0 & 0 & 0 & 0 & 0 & 0 & 0 \\
\hline 3 & CHPS Compound & Rural & Public & 0 & 0 & 0 & 0 & 0 & 0 & 0 \\
\hline 4 & Clinic & Rural & Private & 0 & 0 & 0 & 0 & 0 & 0 & 0 \\
\hline 5 & CHPS Compound & Rural & Public & 84 & 126 & 151 & 126 & 126 & 135 & 150 \\
\hline 6 & Health Centre & Rural & Public & 111 & 119 & 129 & 119 & 119 & 138 & 143 \\
\hline 7 & Health Centre & Rural & Public & 157 & 234 & 183 & 234 & 234 & 206 & 200 \\
\hline 8 & Health Centre & Rural & Public & 183 & 236 & 272 & 236 & 236 & 214 & 209 \\
\hline 9 & Health Centre & Rural & Public & 233 & 241 & 339 & 247 & 247 & 252 & 247 \\
\hline 10 & Health Centre & Rural & Public & 293 & 323 & 311 & 325 & 325 & 266 & 261 \\
\hline 11 & Health Centre & Rural & Public & 324 & 367 & 396 & 377 & 377 & 349 & 376 \\
\hline 12 & CHPS Compound & Rural & Public & 338 & 433 & 485 & 448 & 448 & 415 & 419 \\
\hline 13 & CHPS Compound & Rural & Public & 365 & 391 & 369 & 392 & 392 & 419 & 409 \\
\hline 14 & CHPS Compound & Rural & Public & 472 & 434 & 549 & 445 & 445 & 490 & 481 \\
\hline 15 & CHPS Compound & Rural & Public & 504 & 563 & 601 & 563 & 563 & 553 & 539 \\
\hline 16 & Health Centre & Rural & Public & 526 & 559 & 574 & 557 & 557 & 543 & 527 \\
\hline 17 & Health Centre & Rural & Public & 536 & 523 & 531 & 536 & 536 & 526 & 515 \\
\hline 18 & Health Centre & Rural & Public & 544 & 519 & 588 & 527 & 527 & 552 & 523 \\
\hline 19 & CHPS Compound & Rural & Public & 562 & 519 & 576 & 519 & 519 & 482 & 453 \\
\hline 20 & CHPS Compound & Rural & Public & 593 & 619 & 594 & 626 & 626 & 572 & 541 \\
\hline 21 & Health Centre & Rural & Public & 599 & 625 & 813 & 655 & 655 & 623 & 615 \\
\hline 22 & Health Centre & Rural & Public & 619 & 648 & 614 & 636 & 636 & 656 & 675 \\
\hline 23 & CHPS Compound & Rural & Public & 874 & 715 & 714 & 734 & 734 & 674 & 720 \\
\hline 24 & CHPS Compound & Rural & Public & 893 & 706 & 646 & 751 & 751 & 784 & 785 \\
\hline 25 & Health Centre & Urban & Public & 964 & 1298 & 1280 & 1301 & 1301 & 1487 & 1374 \\
\hline 26 & Clinic & Urban & Public & 1013 & 1057 & 1093 & 1057 & 1057 & 1089 & 1089 \\
\hline Total & & & & 10,787 & 11,255 & 11,808 & 11,411 & 11,411 & 11,425 & 11,251 \\
\hline
\end{tabular}

Source: GHS/DHIMS II (Ho West District, 2015-2017)

Legend: ANC (Antenatal Care); SVDs (Spontaneous Vaginal Deliveries); WIFA (Women in Fertility Age); OPV1 (Oral Polio Vaccine 1); OPV3 (Oral Polio Vaccine 3); Penta1 (Pentavalent 1); Penta 3 (Pentavalent 3); CHPS (Community-based Health Planning and Services)

was 445 in one clinic while the lowest was 3 in one CHPS compound, as shown in Table 2. Figure 1 further illustrates the yearly trend of $\mathrm{MNCH}$ services utilization from 2015 to 2017. Out of the 26 health facilities, 6 (23\%) recorded SVDs even though did not have record of midwife at post which suggests possible unskilled deliveries. The WHO defines unskilled deliveries as births not attended to by doctors, nurses or midwives trained to provide life-saving maternal and newborn care during pregnancy, birth and the postnatal period. The definition includes deliveries by traditional birth attendants or by other auxiliary health workers trained to provide maternal and newborn care [2].

Fifteen (15) out of the 26 health facilities had concurring records of SVDs and midwives at post in the DHIM SII data. Out of this number, the highest cumulative number of SVDs per midwife within the period was 136 while the lowest was 7; one facility had three midwives at post but recorded no SVDs from 2015 to 2017 (see Table 2). Average SVDs per health facility appeared to be highest among urban facilities from 2015 to 2017 (see Table 4). Cumulative number of ANC visits recorded in the DHIMSII from 2015 to 2017 in the 26 facilities was 17,052, ranging from 0 to 3539 per health facility. Many more ANC visits were recorded in rural and public health facilities. Health centres recorded 9381 (55\%) cumulative ANC visits from 2015 to 2017 followed by clinics 4282 (25\%) and CHPS compounds 3389 (20\%) (see Table 4).

Even though the cumulative number of SVDs was 2162, the BCG immunizations record was 10,787 within the same period. Out of the 26 facilities, four (15\%) did not have record any of the childhood immunizations (see Table 3). Average child immunizations per health 


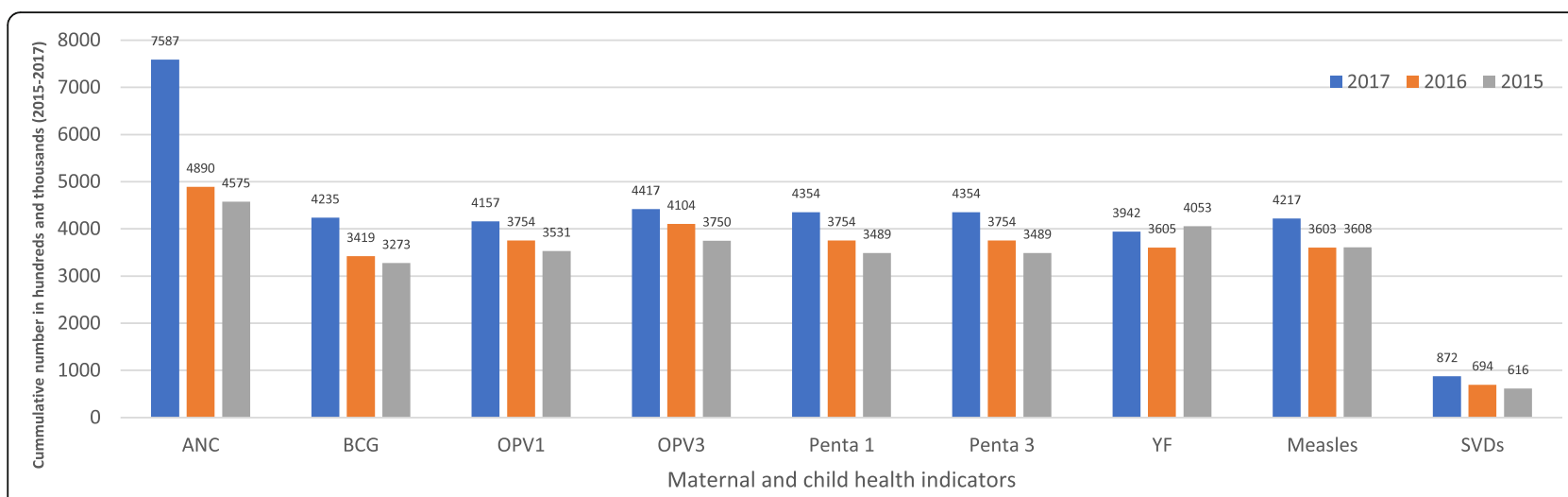

Fig. 1 Aggregated yearly trend in maternal and child health services utilization (2015-2017). GHS/DHIMS II (Ho West District, 2015 - 2017); ANC (Antenatal Care); SVDs (Spontaneous Vaginal Deliveries); OPV1 (Oral Polio Vaccine 1); OPV3 (Oral Polio Vaccine 3); Penta1 (Pentavalent 1); Penta 3 (Pentavalent 3); YF (Yellow Fever)

facility increased marginally over the years (see Fig. 2) with consistently lower BCG service utilization and higher OPV3 utilization (see Table 3). Urban health facilities recorded relatively higher child immunizations than rural health facilities between 2015 and 2017 (see Table 4).

\section{Association between facility-based SVDs and newborn immunization records}

Figure 3 shows the association between number of ANC visits and SVDs per health facility from 2015 to 2017. The DHIMSII records revealed positive association between number of ANC visits recorded in a health facility and the number of SVDs recorded in the pertinent health facility. Thus, facilities which recorded higher
ANC visits from 2015 to 2017 correspondingly recorded higher SVDs and vice versa. In terms of level of care, a positive correlation was also observed between number of ANC visits in a health facility and the number of SVDs recorded in the particular health facility. Publicly owned health centres located in rural areas also recorded higher ANC visits with corresponding high SVDs relative to their comparators, as illustrated in Fig. 4.

Total of 2162 SVDs were recorded in the 26 health facilities from 2015 to 2017 compared to BCG record of 10, 787 within the same time period. A shown in Fig. 5, number of facility-based SVDs recorded in a pertinent health facility did not match with the number of BCGs given at birth; one facility recorded 221 SVDs but had no record of BCG immunizations while another facility recorded 874

Table 4 Average maternal and child health service utilization per health facility: disaggregated by facility location and reference year

\begin{tabular}{|c|c|c|c|c|c|c|}
\hline & \multicolumn{2}{|l|}{2015} & \multicolumn{2}{|l|}{2016} & \multicolumn{2}{|l|}{2017} \\
\hline & Rural & Urban & Rural & Urban & Rural & Urban \\
\hline $\begin{array}{l}\text { Child } \\
\text { immunizations }\end{array}$ & Mean $(95 \% \mathrm{Cl})$ & Mean $(95 \% \mathrm{Cl})$ & Mean $(95 \% \mathrm{Cl})$ & Mean $(95 \% \mathrm{Cl})$ & Mean $(95 \% \mathrm{Cl})$ & Mean $(95 \% \mathrm{Cl})$ \\
\hline $\mathrm{BCG}$ & $120(82$ 158) & $376(58694)^{*}$ & $136(99$ 174) & $210(-6,101029)^{*}$ & 149 (103 196) & $403(212594)^{*}$ \\
\hline OPV1 & $126(94$ 159) & $440(-6,271507)^{*}$ & 142 (109 175) & $313(141484)^{*}$ & 144 (107 181) & $425(-2,101060)^{*}$ \\
\hline OPV3 & 136 (104 168) & $445(-6,671556)^{*}$ & 153 (117 189) & $371(333409)^{*}$ & 151 (114 189) & $471(-3,111252)^{*}$ \\
\hline Penta 1 & $125(93158)$ & $429(-4,991357)^{*}$ & 142 (109 175) & $313(141484)^{*}$ & 151 (111 191) & $438(-3,571232)^{*}$ \\
\hline Penta 3 & $125(93158)$ & $429(-4,991357)^{*}$ & $142(109$ 175) & $313(141484)^{*}$ & 151 (111 191) & $438(-3,571232)^{*}$ \\
\hline Yellow Fever & 143 (103 183) & $528(-12642320)^{*}$ & $134(102$ 166) & $334(137530)^{*}$ & 134 (103 166) & $427(-114967)^{*}$ \\
\hline Measles & $126(92159)$ & $485(-7,541723)^{*}$ & $135(103166)$ & $321(289352)^{*}$ & 146 (109 183) & $427(-114967)^{*}$ \\
\hline WIFA population & $\begin{array}{l}1865(-2,864 \\
017)\end{array}$ & $\begin{array}{l}3305(-12,79419 \\
404)\end{array}$ & $\begin{array}{l}1912(-2923 \\
4117)\end{array}$ & $\begin{array}{l}3389(-12,920 \\
9697)^{*}\end{array}$ & $\begin{array}{l}1955(-2,964 \\
207)\end{array}$ & $\begin{array}{l}3423(-12,64519 \\
490)\end{array}$ \\
\hline ANC attendance & $115(43$ 187) & $907(-1,9213734)^{*}$ & 138 (78 198) & $791(-30024583)^{*}$ & 220 (161 280) & $1148(-10503346)^{*}$ \\
\hline SVDs & 21 (4 38) & $90(-418598)^{*}$ & $23(936)$ & $100(-644843)^{*}$ & $27\left(\begin{array}{lll}16 & 39\end{array}\right)$ & $125(-288537)^{*}$ \\
\hline
\end{tabular}

Source: GHS/DHIMS II (Ho West District, 2015-2017)

Legend: ANC (Antenatal Care); SVDs (Spontaneous Vaginal Deliveries); WIFA (Women in Fertility Age); OPV1 (Oral Polio Vaccine 1); OPV3 (Oral Polio Vaccine 3); Penta1 (Pentavalent 1); Penta 3 (Pentavalent 3)

${ }^{*} p<0.001$ (Poisson regression) statistically significant 


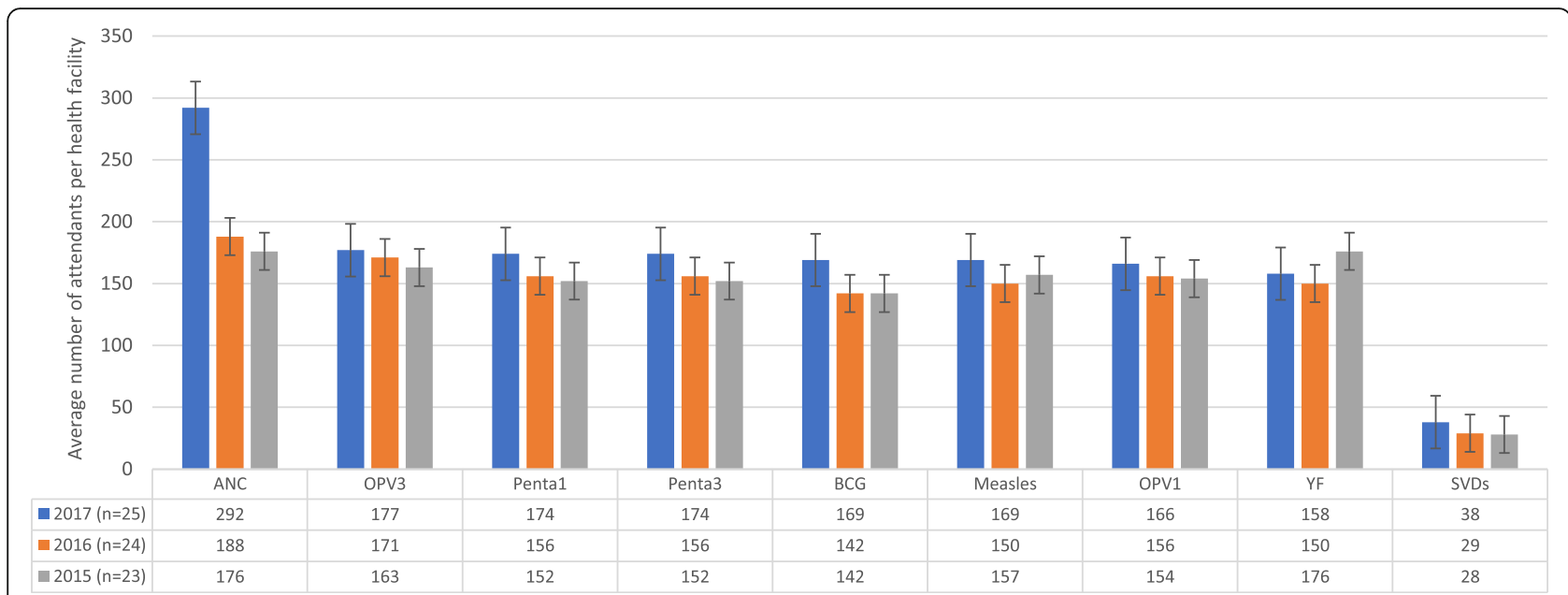

Fig. 2 Average maternal and child health service utilization per health facility: disaggregated by reference year (2015-2017). GHS/DHIMS II (Ho West District, 2015 - 2017); ANC (Antenatal Care); SVDs (Spontaneous Vaginal Deliveries); WIFA (Women in Fertility Age); IRR (Incidence Rate Ratio); Cl (Confidence Interval); OPV1 (Oral Polio Vaccine 1); OPV3 (Oral Polio Vaccine 3); Penta1 (Pentavalent 1); Penta 3 (Pentavalent 3); $n$ (number of health facilities)

BCG immunizations without a record of SVD. Figure 6 shows that cumulatively, higher BCGs and SVDs were recorded in rural facilities relative to urban facilities; public facilities equally recorded higher BCGs and SVDs than private facilities; similarly, higher BCG immunizations were recorded in health centres than CHPS compounds and clinics even though there was no correlation with the cumulative number of SVDs recorded.

\section{Correlates of maternal, newborn and child health (MNCH) services utilization}

Poisson regression model specification in Table 5 was used to predict the determinants of $\mathrm{MNCH}$ services utilization from the DHIMSII data. Output of the regression showed that a unit increase in the number of midwives in a health facility correspondingly increases the number of ANC visits (IRR = 1.30, [95\% CI:1.29, 1.32]; $p=$ 0.0001), and facility-based SVDs (IRR $=1.30$ [95\% CI:1.25, 1.35]; $p=0.0001$ ) in the pertinent health facility, holding other covariates constant. Additionally, a positive correlation was found between high records of ANC visits in a health facility and high number of facility-based SVDs $($ IRR $=1.00$ [95\% CI:0.99, 1.00]; $p=0.0001)$ besides the number of midwives (IRR $=1.14$ [95\% CI:1.09, 1.20]; $p=$ 0.0001 ) and other cadre of frontline health staff (IRR = 1.06 [95\% CI:1.05, 1.07]; $p=0.0001$ ) (see Table 6).

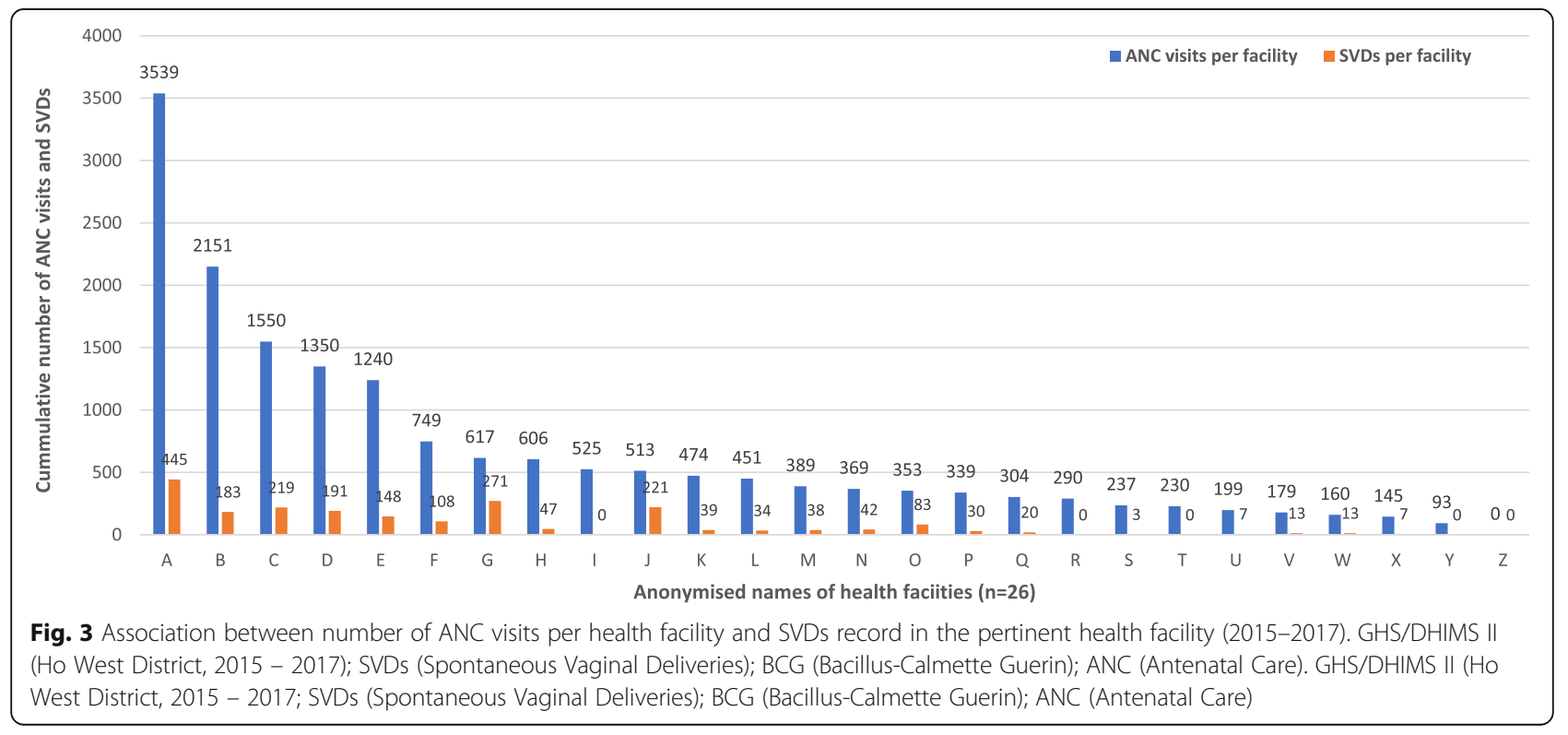




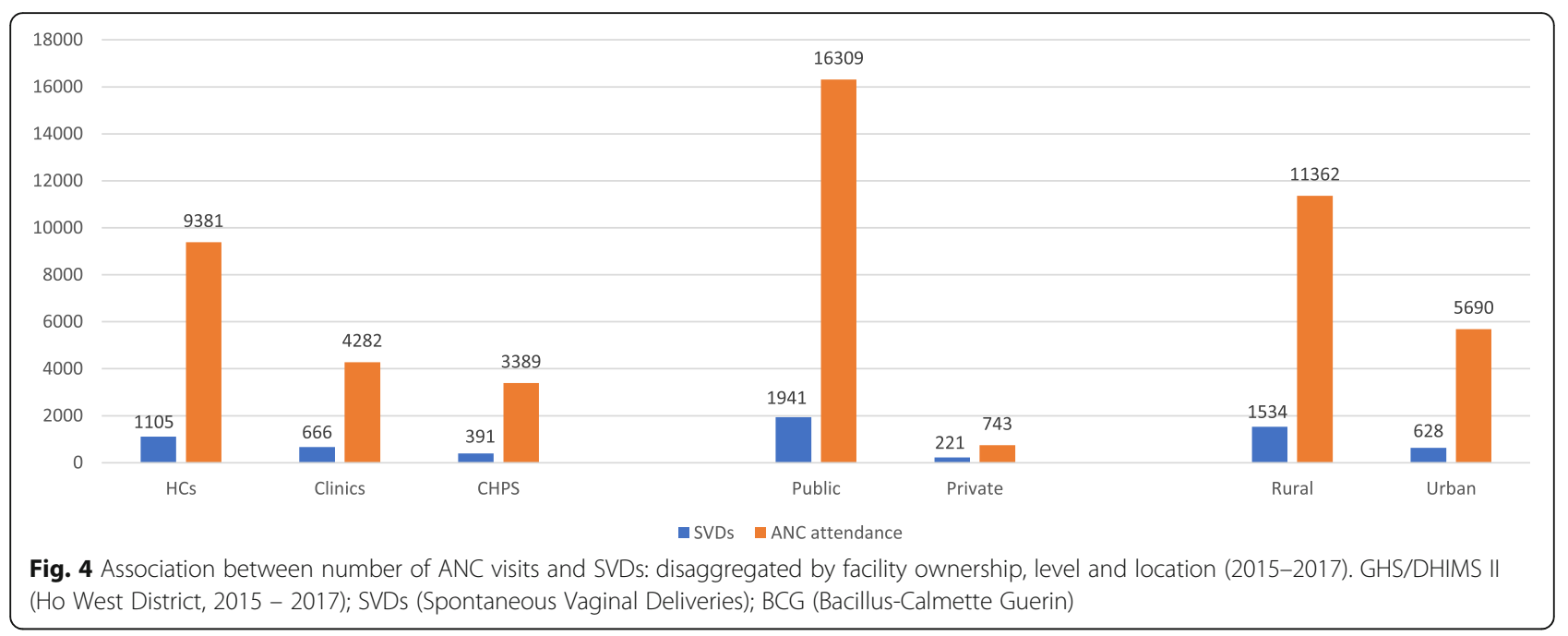

A positive correlation was also observed between the number of midwives per health facility and the number of childhood immunizations: BCG, OPV1, OPV3, Penta1, Penta3, YF and Measles $(p<0.0001)$; high number of midwives in a health facility also had a positive correlation with the number of records on child immunizations $(p<0.0001)$. Similarly, there was a positive association between rural location of a health facility and utilization of childhood immunizations relative to urban facilities $(p<0.0001)$, holding other covariates constant (see Table 7).

\section{Discussion}

Global efforts towards attainment of universal health coverage has been largely progressive, albeit the pace in low- and middle-income countries (LMICs) is comparatively slow [3]. Studies on continuum of care $(\mathrm{CoC})$ for $\mathrm{MNCH}$ services abound in Ghana [7-12] but there are no known ecological studies on the topic area using the DHIMSII data set from a predominantly rural district in the Volta Region of Ghana. The existing gap in the literature thus makes this study relevant and timely.

Results from this study have demonstrated that $\mathrm{MNCH}$ service utilization, are significantly associated with rural-urban differentials and distribution of human and material health resources as alluded to in previous studies on Ghana [13-16] and other countries [16, 17]. Density of midwives and other frontline health staff significantly correlated with number of ANC visits recorded in the study health facilities over the three-year period, contrary to findings by similar studies on Ghana $[9,18,19]$ and other countries $[20,21]$, which reported that the number of frontline health workers per se did not enhance utilization of maternal and child health services. These studies argue that poor attitudes of staff and other health system challenges remain important constraints to utilization of maternal, newborn and child health $(\mathrm{MNCH})$ services in Ghana [16, 22-30].

Even though poor attitude of health staff towards their clients is widely documented as an important

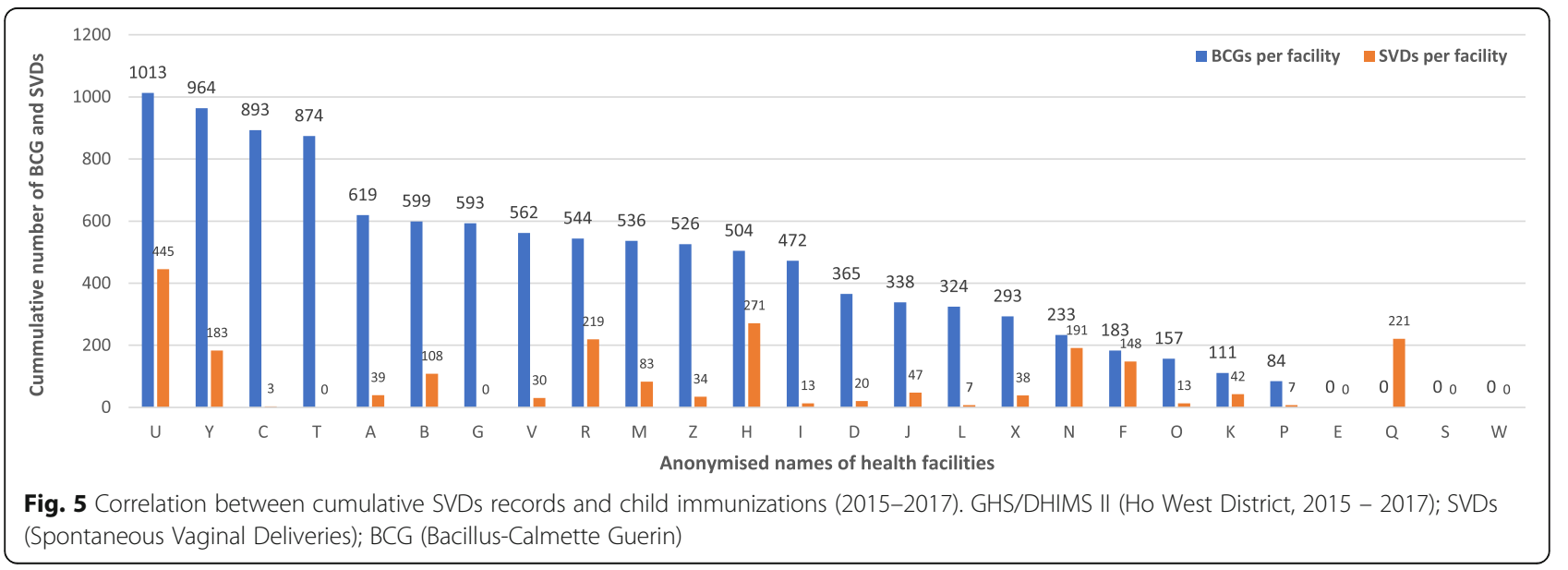




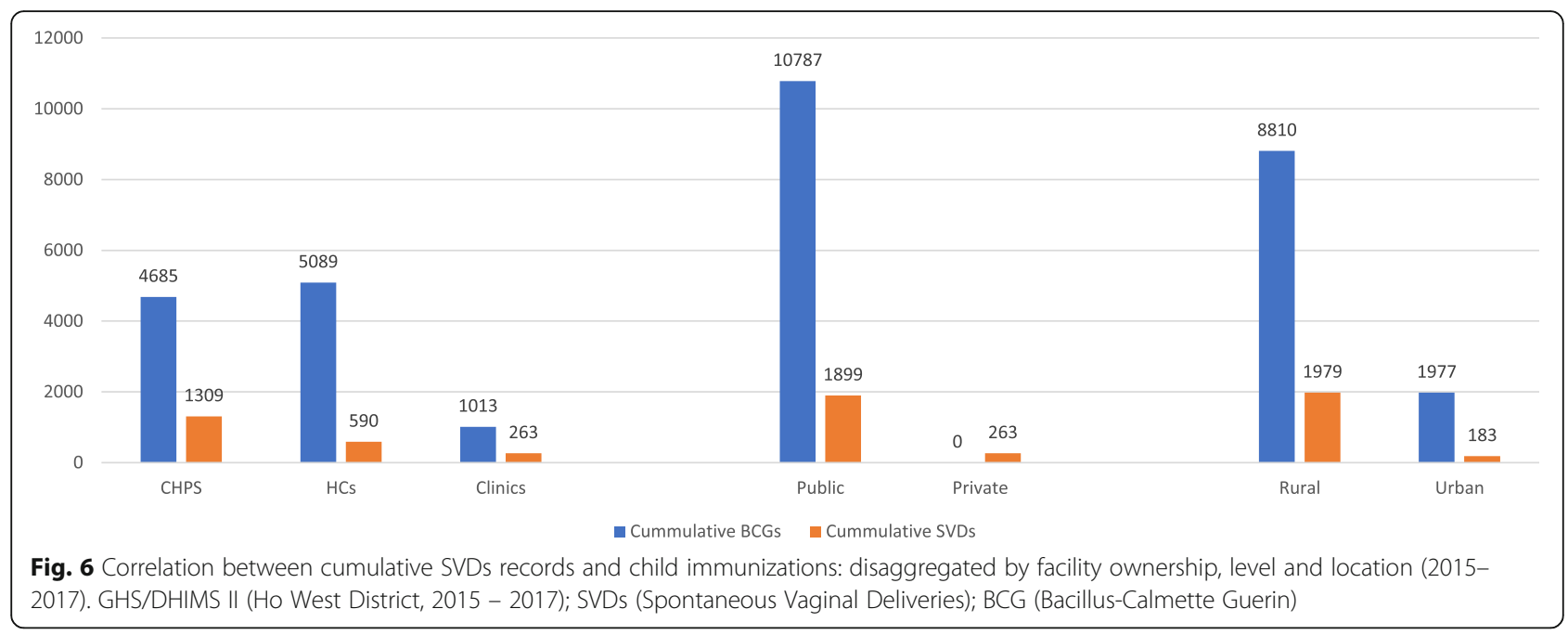

disincentive to many healthcare clients to utilize safer healthcare services, rural communities often do not have alternatives to the only available healthcare providers. Consequently, higher health services utilization in rural locations is not always a function of improved healthcare delivery system but a reflection of lack of choice for better alternatives. Indeed, other barriers to $\mathrm{MNCH}$ service utilization not explored in this study are acknowledged in terms of long travel times to health facilities [24, 26, 29], socio-cultural beliefs $[16,23,30,31]$ and financial inaccessibility [32-37].

This study therefore recognizes these existing challenges while underscoring the continued critical role of health sector human resources towards improving

Table 5 Model specification for Poisson regression analyses: disaggregated by reference year (2015-2017)

\begin{tabular}{|c|c|c|c|c|c|c|c|}
\hline \multirow{3}{*}{ Variables } & \multirow{3}{*}{ Variable definition } & \multicolumn{6}{|c|}{ Summary statistics } \\
\hline & & \multicolumn{2}{|l|}{2015} & \multicolumn{2}{|l|}{2016} & \multicolumn{2}{|l|}{2017} \\
\hline & & Obs. & Mean (SD) & Obs. & Mean (SD) & Obs. & Mean (SD) \\
\hline \multicolumn{8}{|c|}{ Outcome variables (maternal) } \\
\hline ANC attendance & Number of women attending ANC & 23 & $27(43)$ & 24 & $29(41)$ & 25 & $35(38)$ \\
\hline SVDs & Number of supervised deliveries for SVDs & 23 & $142(108)$ & 24 & $142(86)$ & 25 & $169(125)$ \\
\hline \multicolumn{8}{|c|}{ Outcome variables (child) } \\
\hline OPV1 & Number of children receiving OPV1 vaccine & 23 & $154(116)$ & 24 & $156(86)$ & 25 & $166(113)$ \\
\hline OPV3 & Number of children receiving OPV3 vaccine & 23 & $163(114)$ & 24 & $171(99)$ & 25 & $177(123)$ \\
\hline Penta1 & Number of children receiving Penta 1 vaccine & 23 & $152(113)$ & 24 & $156(86)$ & 25 & $174(120)$ \\
\hline Penta3 & Number of children receiving Penta 3 vaccine & 23 & $152(113)$ & 24 & $156(86)$ & 25 & $174(120)$ \\
\hline Yellow fever (YF) & Number of children receiving YF vaccine & 23 & $176(146)$ & 24 & $150(89)$ & 25 & $158(108)$ \\
\hline Measles & Number of children receiving measles vaccine & 23 & $157(146)$ & 24 & $150(86)$ & 25 & $169(113)$ \\
\hline \multicolumn{8}{|l|}{ Covariates } \\
\hline Public $^{a}$ & 1 of public health facility & 26 & $0.92(0.27)$ & 26 & $0.92(0.27)$ & 26 & $0.92(0.27)$ \\
\hline Private & 0 if private health facility (Reference) & 26 & $0.08(0.27)$ & 26 & $0.08(0.27)$ & 26 & $0.08(0.27)$ \\
\hline Rural & 1 if rural health facility & 26 & $0.92(0.27)$ & 26 & $0.92(0.27)$ & 26 & $0.92(0.27)$ \\
\hline Urban & 0 if urban health facility (Reference) & 26 & $0.08(0.27)$ & 26 & $0.08(0.27)$ & 26 & $0.08(0.27)$ \\
\hline Midwives per clinic & Number of midwives per clinic & 26 & $0.23(0.43)$ & 26 & $0.73(0.87)$ & 26 & $0.88(1.37)$ \\
\hline Other staff & Number of other health staff per clinic & 25 & $3(2)$ & 25 & $3(3)$ & 25 & $4(4)$ \\
\hline WIFA population & Number of catchments WIFA population & 26 & 1976 (4915) & 26 & $2025(5038)$ & 26 & $2068(5142)$ \\
\hline
\end{tabular}

Source: GHS/DHIMS II (Ho West District, 2015-2017)

Legend: ANC (Antenatal Care); SVDs (Spontaneous Vaginal Deliveries); WIFA (Women in Fertility Age); IRR (Incidence Rate Ratio); CI (Confidence Interval); OPV1 (Oral Polio Vaccine 1); OPV3 (Oral Polio Vaccine 3); Penta1 (Pentavalent 1); Penta 3 (Pentavalent 3); SD (Standard Deviation)

a Variable dropped from Poisson regression models for multicollinearity 
Table 6 Determinants of maternal healthcare services utilization based on cumulative three-year reference data (2015-2017)

\begin{tabular}{|c|c|c|c|}
\hline \multirow{2}{*}{$\begin{array}{l}\text { Midwives per clinic and ANC attendance (Poisson Regression Model 1) } \\
\text { Independent Variables }\end{array}$} & \multicolumn{3}{|c|}{ Dependent Variable: ANC (2015-2017) } \\
\hline & IRR & $(95 \% \mathrm{Cl})$ & $p$-value \\
\hline Midwives per clinic & 1.30 & 1.291 .32 & 0.000 \\
\hline WIFA population & 0.99 & 0.991 .00 & 0.000 \\
\hline Other staff per clinic & 1.05 & 1.041 .05 & 0.000 \\
\hline Rural & 1.24 & 1.151 .34 & 0.000 \\
\hline Urban & 1.0 & 1.0 & 1.0 \\
\hline Log pseudolikelihood & \multicolumn{3}{|l|}{-577.75} \\
\hline LR chi2(4) & \multicolumn{3}{|l|}{1663.40} \\
\hline Prob > chi2 & \multicolumn{3}{|l|}{0.0000} \\
\hline Pseudo R2 & \multicolumn{3}{|l|}{0.5901} \\
\hline Obs. & \multicolumn{3}{|l|}{23} \\
\hline Midwives per clinic and SVDs (Poisson Regression Model 2) & \multicolumn{3}{|c|}{ Dependent Variable: SVDs (2015-2017) } \\
\hline Independent Variables & IRR & $(95 \% \mathrm{Cl})$ & $p$-value \\
\hline Midwives per clinic & 1.30 & 1.251 .35 & 0.000 \\
\hline WIFA population & 0.99 & 0.991 .00 & 0.000 \\
\hline Other staff per clinic & 1.08 & 1.071 .09 & 0.000 \\
\hline Rural & 0.35 & 0.190 .65 & 0.001 \\
\hline Urban & 1.0 & 1.0 & 1.0 \\
\hline Log pseudolikelihood & \multicolumn{3}{|l|}{-577.75132} \\
\hline LR chi2(4) & \multicolumn{3}{|l|}{1663.40} \\
\hline Prob > chi2 & \multicolumn{3}{|l|}{0.0000} \\
\hline Pseudo R2 & \multicolumn{3}{|l|}{0.5901} \\
\hline Obs. & \multicolumn{3}{|l|}{23} \\
\hline ANC attendance and SVDs (Poisson Regression Model 3) & \multicolumn{3}{|c|}{ Dependent Variable: SVDs (2015-2017) } \\
\hline Independent Variables & IRR & $(95 \% \mathrm{Cl})$ & $p$-value \\
\hline ANC attendance & 1.00 & 0.991 .00 & 0.000 \\
\hline Midwives per clinic & 1.14 & 1.091 .20 & 0.000 \\
\hline WIFA population & 0.99 & 0.991 .00 & 0.000 \\
\hline Other staff per clinic & 1.06 & 1.051 .07 & 0.000 \\
\hline Rural & 0.90 & 0.461 .77 & 0.758 \\
\hline Urban & 1.0 & 1.0 & 1.0 \\
\hline Log pseudolikelihood & -530.23193 & & \\
\hline LR chi2(4) & 1758.44 & & \\
\hline Prob > chi2 & 0.0000 & & \\
\hline Pseudo R2 & 0.6238 & & \\
\hline Obs. & 23 & & \\
\hline
\end{tabular}

Source: GHS/DHIMS II (Ho West District, 2015-2017)

Legend: ANC (Antenatal Care); SVDs (Spontaneous Vaginal Deliveries); WIFA (Women in Fertility Age); IRR (Incidence Rate Ratio); CI (Confidence Interval) ${ }^{*} p<0.001$ (Poisson regression) statistically significant

universal access to $\mathrm{MNCH}$ services [25, 27, 28, 38-41]. As demonstrated in this study, facility-based SVDs over the three-year period correlated positively with number of midwives in the pertinent health facility and the cumulative number of ANC visits recorded in the particular health facility. Sheff et al. [42] arrived at similar conclusions in their study on maternal and child health services utilization in the Volta Region.

The evidence demonstrated in this paper presents an empirical basis for Ghana to invest more in health sector human resources particularly as part of the strategic plan to achieve universal access to basic healthcare services. 
Table 7 Determinants of child health service utilization based on cumulative three-year reference data (2015-2017)

\begin{tabular}{|c|c|c|c|c|c|c|c|}
\hline \multirow[b]{2}{*}{$\begin{array}{l}\text { Independent } \\
\text { Variables }\end{array}$} & \multicolumn{7}{|c|}{ Dependent Variables (child immunizations) } \\
\hline & $\begin{array}{l}\text { BCG } \\
\text { (Univariate I) }\end{array}$ & $\begin{array}{l}\text { OPV1 } \\
\text { (Univariate II) }\end{array}$ & $\begin{array}{l}\text { OPV3 } \\
\text { (Univariate III) }\end{array}$ & $\begin{array}{l}\text { Penta1 } \\
\text { (Univariate IV) }\end{array}$ & $\begin{array}{l}\text { Penta3 } \\
\text { (Univariate V) }\end{array}$ & $\begin{array}{l}\text { YF } \\
\text { (Univariate VI) }\end{array}$ & $\begin{array}{l}\text { Measles } \\
\text { (Univariate VII) }\end{array}$ \\
\hline & IRR $(95 \% \mathrm{Cl})$ & IRR (95\% CI) & IRR $(95 \% \mathrm{Cl})$ & IRR $(95 \% \mathrm{CI})$ & IRR $(95 \% \mathrm{CI})$ & IRR $(95 \% \mathrm{Cl})$ & IRR $(95 \% \mathrm{Cl})$ \\
\hline Midwives per clinic & $1.32(1.291 .34)^{*}$ & $1.25(1.221 .27)^{*}$ & $1.25(1.231 .27)^{*}$ & $1.25(1.230 .27)^{*}$ & $1.25(1.231 .27)^{*}$ & $1.25(1.221 .27)^{*}$ & $1.25(1.231 .27)^{*}$ \\
\hline WIFA population & $1.00(1.001 .00)^{*}$ & $1.00(1.001 .00)^{*}$ & $1.00(1.001 .00)^{*}$ & $1.00(1.001 .00)^{*}$ & $\begin{array}{l}1.00(1.00 \\
1.000)^{*}\end{array}$ & $\begin{array}{l}1.00(1.00 \\
1.000)^{*}\end{array}$ & $1.00(1.001 .00)^{*}$ \\
\hline Other staff per clinic & $0.96(0.960 .97)^{*}$ & $0.97(0.970 .98)^{*}$ & $0.98(0.980 .98)^{*}$ & $0.97(0.970 .98)^{*}$ & $0.97(0.970 .98)^{*}$ & $0.97(0.970 .98)^{*}$ & $0.97(0.970 .98)^{*}$ \\
\hline Rural & $\begin{array}{l}68.56(53.22 \\
88.32)^{*}\end{array}$ & $\begin{array}{l}23.41(18.30 \\
29.96)^{*}\end{array}$ & $\begin{array}{l}22.21(17.48 \\
28.22)^{*}\end{array}$ & $\begin{array}{l}25.06(19.62 \\
32.01)^{*}\end{array}$ & $\begin{array}{l}25.06(19.62 \\
32.01)^{*}\end{array}$ & $\begin{array}{l}22.52(17.60 \\
28.82)^{*}\end{array}$ & $\begin{array}{l}24.23(18.91 \\
31.05)^{*}\end{array}$ \\
\hline Urban & 1.0 & 1.0 & 1.0 & 1.0 & 1.0 & 1.0 & 1.0 \\
\hline $\begin{array}{l}\text { Log } \\
\text { pseudolikelihood }\end{array}$ & -564.57 & -515.93 & -616.18 & -517.88 & -517.88 & -510.56 & -496.04 \\
\hline LR chi2(4) & 3310.25 & 3247.38 & 3014.44 & 3292.27 & 3292.27 & 3767.78 & 3548.59 \\
\hline Prob > chi2 & 0.0105 & 0.0000 & 0.0000 & 0.0000 & 0.0000 & 0.0000 & 0.0000 \\
\hline Pseudo R2 & 0.7457 & 0.7589 & 0.7098 & 0.7607 & 0.7607 & 0.7868 & 0.7815 \\
\hline Obs. & 23 & 23 & 23 & 23 & 23 & 23 & 23 \\
\hline ANC attendance & $1.00(1.001 .00)^{*}$ & $1.00(1.001 .00)^{*}$ & $1.00(1.001 .00)^{*}$ & $1.00(1.001 .00)^{*}$ & $1.00(1.001 .00)^{*}$ & $1.00(1.001 .00)^{*}$ & $1.00(1.001 .00)^{*}$ \\
\hline Midwives per clinic & $1.24(1.211 .27)^{*}$ & $1.19\left(1.171 .22^{*}\right.$ & $1.16(1.141 .19)^{*}$ & $1.19(1.171 .22)^{*}$ & $1.19(1.171 .22)^{*}$ & $1.19(1.171 .22)^{*}$ & $1.00(1.001 .00)^{*}$ \\
\hline WIFA population & $1.00(1.001 .00)^{*}$ & $1.00(1.001 .00)^{*}$ & $1.00(1.001 .00)^{*}$ & $1.00(1.001 .00)^{*}$ & $1.00(1.001 .00)^{*}$ & $1.00(1.001 .00)^{*}$ & $1.20(1.171 .23)^{*}$ \\
\hline Other staff per clinic & $0.96(0.960 .96)^{*}$ & $0.97(0.970 .98)^{*}$ & $0.98(0.970 .98)^{*}$ & $0.97(0.970 .97)^{*}$ & $0.97(0.970 .97)^{*}$ & $0.97(0.970 .98)^{*}$ & $1.00(1.001 .00)^{*}$ \\
\hline Rural & $\begin{array}{l}90.18(69.42 \\
7.16)^{*}\end{array}$ & $\begin{array}{l}28.64(22.20 \\
36.96)^{*}\end{array}$ & $\begin{array}{l}31.33(24.44 \\
0.16)^{*}\end{array}$ & $\begin{array}{l}30.87(23.97 \\
39.76)^{*}\end{array}$ & $\begin{array}{l}30.87(23.97 \\
39.76)^{*}\end{array}$ & $\begin{array}{l}27.74(21.49 \\
35.79)^{*}\end{array}$ & $0.97(0.970 .98)^{*}$ \\
\hline Urban & 1.0 & 1.0 & 1.0 & 1.0 & 1.0 & 1.0 & 1.0 \\
\hline $\begin{array}{l}\text { Log } \\
\text { pseudolikelihood }\end{array}$ & -526.61 & -495.29 & -553.65 & -495.41 & -495.41 & -488.83 & -477.05 \\
\hline LR chi2(4) & 3386.18 & 3288.67 & 3139.51 & 3337.21 & 3337.21 & 3811.23 & 3586.56 \\
\hline Prob > chi2 & 0.0000 & 0.0000 & 0.0000 & 0.0000 & 0.0000 & 0.0000 & 0.0000 \\
\hline Pseudo R2 & 0.7628 & 0.7685 & 0.7393 & 0.7711 & 0.7711 & 0.7958 & 0.7899 \\
\hline Obs. & 23 & 23 & 23 & 23 & 23 & 23 & 23 \\
\hline SVDs & $1.00(1.001 .00)^{*}$ & $1.00(1.001 .00)^{*}$ & $1.00(1.001 .00)^{*}$ & $1.00(1.001 .00)^{*}$ & $1.00(1.001 .00)^{*}$ & $1.00(1.001 .00)^{*}$ & $1.00\left(\begin{array}{lll}1.00 & 1.00)^{*}\end{array}\right.$ \\
\hline Midwives per clinic & $1.29(1.261 .32)^{*}$ & $1.22(1.201 .25)^{*}$ & $1.20(1.181 .23)^{*}$ & $1.22(1.201 .25)^{*}$ & $1.22(1.201 .25)^{*}$ & $1.22(1.191 .24)^{*}$ & $1.23(1.201 .26)^{*}$ \\
\hline WIFA population & $1.00(1.001 .00)^{*}$ & $1.00(1.001 .00)^{*}$ & $1.00(1.001 .00)^{*}$ & $1.00(1.001 .00)^{*}$ & $1.00(1.001 .00)^{*}$ & $1.00(1.001 .00)^{*}$ & $1.00(1.001 .00)^{*}$ \\
\hline Other staff per clinic & $0.96(0.960 .96)^{*}$ & $0.97(0.970 .98)^{*}$ & $0.98(0.970 .98)^{*}$ & $0.97(0.970 .97)^{*}$ & $0.97(0.970 .97)^{*}$ & $0.97(0.970 .98)^{*}$ & $0.97(0.970 .98)^{*}$ \\
\hline Rural & $\begin{array}{l}72.05(55.80 \\
3.03)^{*}\end{array}$ & $\begin{array}{l}24.39(19.02 \\
31.27)^{*}\end{array}$ & $\begin{array}{l}24.13(18.94 \\
30.74)^{*}\end{array}$ & $\begin{array}{l}26.14(20.42 \\
33.45)^{*}\end{array}$ & $\begin{array}{l}26.14(20.42 \\
3.45)^{*}\end{array}$ & $\begin{array}{l}23.74(18.51 \\
30.45)^{*}\end{array}$ & $\begin{array}{l}25.18(19.61 \\
32.32)^{*}\end{array}$ \\
\hline Urban & 1.0 & 1.0 & 1.0 & 1.0 & 1.0 & 1.0 & 1.0 \\
\hline $\begin{array}{l}\text { Log } \\
\text { pseudolikelihood }\end{array}$ & -557.24 & -510.62 & -592.31 & -512.20 & -512.20 & -502.36 & -491.71 \\
\hline LR chi2(4) & 3324.93 & 3258.00 & 3062.20 & 3303.63 & 3303.63 & 3784.17 & 3557.25 \\
\hline Prob > chi2 & 0.0000 & 0.0000 & 0.0000 & 0.0000 & 0.0000 & 0.0000 & 0.0000 \\
\hline Pseudo R2 & 0.7490 & 0.7613 & 0.7211 & 0.7633 & 0.7633 & 0.7902 & 0.7834 \\
\hline Obs. & 23 & 23 & 23 & 23 & 23 & 23 & 23 \\
\hline
\end{tabular}

Source: GHS/DHIMS II (Ho West District, 2015-2017)

Legend: ANC (Antenatal Care); SVDs (Spontaneous Vaginal Deliveries); WIFA (Women in Fertility Age); IRR (Incidence Rate Ratio); CI (Confidence Interval) ${ }^{*} p<0.001$ (Poisson regression) statistically significant

This long-term crucial investment, alongside ongoing interventions, could prove useful towards achieving the SDG 3 targets in Ghana and other resource constrained countries in Africa [3]. Although poor attitude of health professionals and the negative effect on universal access to healthcare remain a barrier to optimal health service 
utilization $[22,25,27,31]$, the available evidence suggests frontline health personnel remain an indispensable piece of the puzzle to overcoming this challenge in health systems. Indeed, the WHO tenets on universal health coverage emphasizes the vital role of frontline healthcare professionals in transforming health systems across the globe [38].

Another revelation from the analyzed data was the fact that consistently, the cumulative numbers of facilitybased SVDs, ANC visits and child immunizations increased marginally from 2015 to 2017 . The trend largely reflects the national picture in Ghana which portrays a yearly marginal increase in the utilization of $\mathrm{MNCH}$ services [41].

The positive association observed between high ANC visits and facility-based SVDs in the DHIMSII data also corroborates conclusions in previous studies on Ghana. Systematic reviews $[7,10]$ and empirical studies $[11-13$, 17, 22] on Ghana observed that mothers who recorded at least four (4) ANC visits were more likely to experience facility-based SVD and remain in the CoC for postnatal care including child health services than mothers who recorded less ANC visits.

Finally, it is imperative to state that this study design differs significantly from these previous studies and does not allow for direct comparison of the outcomes. Also, conclusions on retention and dropout from the $\mathrm{CoC}$ cannot be made in this study because, the data set was not on individual registrants or attendants. Instead, the data entailed aggregated cumulative figures from the 26 primary healthcare facilities in the study district. In light of this acknowledged limitation, individual level conclusions will amount to an ecological fallacy since generalizations cannot be made on individuals from the pool of data reported in the DHIMSII. Nonetheless, the cumulative data from the various health facilities gives a global picture of trends and associated factors of $\mathrm{MNCH}$ services utilization. This wholistic view will help to inform district level health policy decisions and trigger followup empirical studies to understand specific facility level details on the topic.

\section{Conclusion}

Coverage for maternal and child health services in the study district marginally increased over the three-year period, albeit evidence of $23 \%$ of the study facilities recording unskilled deliveries was discovered. The aggregate DHIMSII data found compelling evidence of a positive association between high records of ANC visits in the study facilities and the cumulative records of facility-based SVDs; likewise, higher records of ANC visits and facility-based SVDs correlated positively with the cumulative number of child immunizations. Additionally, number of frontline health staff (especially midwives) in a health facility and geographic location of the pertinent facility had positive associations with $\mathrm{MNCH}$ services utilization. Although these findings are largely informed by ecological population-based aggregate data, the evidence remain compelling and should stimulate actions for district level policy dialogues and further epidemiological enquiries through mixedmethods research designs to unearth facility-level peculiarities on the determinants of $\mathrm{MNCH}$ services utilization in the study region and possibly replicated to other parts of the country.

\section{Implications for health policy}

In light of the above findings, the following policy recommendations are proposed:

1. DHIMSII data remains a vital data source that should be leveraged to informed evidence-based policy decisions backed by relevant empirical studies. Annual regional performance reviews should therefore compel regions and districts to report on scientific outputs from the DHIMSII as part of their performance assessment criteria.

2. Unskilled deliveries remain a challenge in many deprived districts in Ghana as demonstrated in this study, there is therefore the need for enhanced efficiencies in the allocation and distribution of skilled personnel to improve the situation. Targeted staff motivation schemes will attract and retain qualified health staff to deprived communities in the country.

3. Therefore is the need for accelerated targeted support system for pregnant mothers and their partners to help in enrollment and retention of mothers in the $\mathrm{CoC}$ for $\mathrm{MNCH}$ services.

\section{Limitations of the study}

This study relied mainly on ecological population-based data from DHIMSII without the benefit of complementary primary data to unearth clients' and healthcare providers' personal experiences in respect of service quality gaps and the consequent effect on utilization of $\mathrm{MNCH}$ services. Conclusions from this study are therefore not informed by individual personal health information. The figures on $\mathrm{MNCH}$ service indicators are cumulative aggregates reported over a three-year period in all the 26 facilities in the study district. Also, since the DHIMSII data has limitations of possible entry errors and misreporting that are often difficult to detect, perhaps some of the figures might have been over or under reported.

Finally, the results of the DHIMSII might have been skewed by the case management trends of these lower level facilities. Nonetheless, the three-year data period (2015-2017) gives reasonable global picture of the 
$\mathrm{MNCH}$ services utilization trends which is capable of informing further similar investigations in other districts and regions. Future research could therefore consider triangulating primary and secondary data collection approaches for a better appreciation of the depth of this explorative endeavour.

\section{Supplementary information}

Supplementary information accompanies this paper at https://doi.org/10. 1186/s12884-020-03195-1.

\section{Additional file 1.}

\section{Abbreviations}

ANC: Antenatal care; BCG: Bacillus calmette guerin; CoC: Continuum of care; CHPS: Community-based health planning and services; $\mathrm{CHO}$ : Community health officer; DHIMS II: District health information management system II; DPT: Diphtheria pertussis tetanus; GHS: Ghana health service; HWD: Ho west district: IRR: Incidence rate ratio; MMR: Maternal mortality ratio; MNCH: Maternal, newborn and child health; MoH: Ministry of health; OLS: Ordinary least squares; OPV1: Oral polio vaccine 1; OPV3: Oral polio vaccine 3; Penta1: Pentavalent 1; Penta3: Pentavalent 3; PHC: Population and housing census; SDG: Sustainable development goals; SVDs: Spontaneous vaginal deliveries; VIF: Variance inflation factor; WHO: World health organization; WIFA: Women in fertile age; YF: Yellow fever

\section{Acknowledgements}

This study was conducted with the support of the Ho West District Health Directorate in the Volta region. The support of the district health information office is also acknowledged.

\section{Authors' contributions}

Conceived and designed the experiments: RKA AA Performed the experiments; RKA NA Analyzed the data; AA EA EK Contributed materials/ analysis tools; RKA Wrote the paper; SO EKA MG NA MEA AA Peer-reviewed paper. All authors have read and approved the manuscript.

\section{Funding}

No funding for this study.

\section{Availability of data and materials}

All relevant data are within the manuscript and its Supporting Information files.

\section{Ethics approval and consent to participate}

The study used mainly secondary data and did not at any stage collect primary data from respondents. Formal ethics approval was not applicable in this study in line with guidelines of ethics committees in Ghana since the study did not involve primary data on human or animal subjects. Codes were used to replace facility names in the data set to protect the identify and anonymity of these facilities.

Also, administrative approval was sought from the District Health Directorate of the Ho West District and access to data was provided by the District Director of Health Services at the time of conducting this study.

\section{Consent for publication}

Not applicable.

\section{Competing interests}

The authors declare that they have no competing interests.

\section{Author details}

'Institute of Health Research, University of Health and Allied Sciences, Ho, Ghana. ${ }^{2}$ Ghana AIDS/STI Control Programme, Ghana Health Service, Accra, Ghana. ${ }^{3}$ Department of Quality Assurance and Safety, Ghana Health Service, Accra, Ghana. ${ }^{4}$ Department of Economics, University of Ghana, Legon, Accra, Ghana. ${ }^{5} \mathrm{Ho}$ West District Health Directorate, Volta Region, Ho, Ghana.
Received: 8 May 2020 Accepted: 20 August 2020

Published online: 17 September 2020

\section{References}

1. United Nations (UN). (2019). The Sustainable Development Goals Report, 2019., New York, NY, 10017, United States of America. ISBN: 978-92-1101403-7.

2. World Health Organization (WHO). Atlas of African Health Statistics 2018: universal health coverage and the Sustainable Development Goals in the WHO African Region. Brazzaville: WHO Regional Office for Africa; 2018. License: CC BY-NC-SA 3.0 IGO.

3. World Health Organization (WHO). World health statistics overview 2019: monitoring health for the SDGs, sustainable development goals. Geneva: World Health Organization; (WHO/DAD/2019.1); 2019. License: CC BY-NC-SA $3.0 \mathrm{IGO}$.

4. Ghana Health Service (GHS). The health sector in Ghana: facts and figures. Accra Ghana; 2019.

5. Cameron AC, Trivedi PK. Regression analysis of count data. 2nd ed. New York: Cambridge University Press; 2013.

6. Faraway, J. J. Chapter 4: Problems with the predictors. in Linear Models with R (CRC Press,2004).

7. Kikuchi K, Ansah EK, Okawa S, Enuameh Y, Yasuoka J, Nanishi K, et al. Effective linkages of continuum of Care for Improving Neonatal, perinatal, and maternal mortality: a systematic review and meta-analysis. PLoS One. 2015a;10(9):e0139288.

8. Kikuchi K, Ansah E, Okawa S, Shibanuma A, Gyapong M, Owusu-Agyei S, Jimba M. Ghana's Ensure Mothers and Babies Regular Access to Care (EMBRACE) program: study protocol for a cluster randomized controlled trial. Trials. 2015;16(1):22.

9. Yeji F, Shibanuma A, Oduro A, Debpuur C, Kikuchi K, Owusu-Agei S, Nanishi $K$. Continuum of care in a maternal, newborn and child health program in Ghana: low completion rate and multiple obstacle factors. PloS one. 2015; 10(12):e0142849.

10. Enuameh YAK, Okawa S, Asante KP, Kikuchi K, Mahama E, Ansah E, et al. Factors influencing health facility delivery in predominantly rural communities across the three ecological zones in Ghana: a cross-sectional study. PLoS One. 2016;11(3):e0152235.

11. Shibanuma A, Yeji F, Okawa S, et al. The coverage of continuum of care in maternal, newborn and child health: a cross-sectional study of woman-child pairs in Ghana. BMJ Glob Health. 2018:3:e000786.

12. Okawa S, Gyapong M, Leslie $H$, et al. Effect of continuum-of-care intervention package on improving contacts and quality of maternal and newborn healthcare in Ghana: a cluster randomized controlled trial. BMJ Open. 2018:9:e025347.

13. Asuman D, Ackah CG, Enemark U. Inequalities in child immunization coverage in Ghana: evidence from a decomposition analysis. Health Econ Rev. 2018:8:9.

14. Zhang C, Rahman MS, Rahman MM, Yawson AE, Shibuya, K. Trends and projections of universal health coverage indicators in Ghana, 1995-2030: A national and subnational study. PloS one. 2019;14(5):e0209126.

15. Sowe A, Johansson K. Disentangling the rural-urban immunization coverage disparity in the Gambia: a Fairlie decomposition. Vaccine. 2019;37(23):3088-96.

16. Moyer CA, Adongo PB, Aborigo RA, Hodgson A, Engmann CM, DeVries R. "It's up to the woman's people": how social factors influence facility-based delivery in rural northern Ghana. Matern Child Health J. 2014:18(1):109-19.

17. Donfouet HPP, Agesa G, Mutua MK. Trends of inequalities in childhood immunization coverage among children aged 12-23 months in Kenya, Ghana, and Côte d'Ivoire. BMC Public Health. 2019;19(1):988.

18. Arthur E. Wealth and antenatal care use: implications for maternal health care utilisation in Ghana. Health economics review. 2012;2(1):14.

19. Boah M, Adampah T, Jin B, Wan S, Mahama AB, Hyzam D, Akiti C. "I couldn't buy the items so I didn't go to deliver at the health facility" home delivery among rural women in northern Ghana: a mixed-method analysis. PLoS One. 2020;15(3):e0230341.

20. Mizan S, Rahman MM, Safii R, Ahmad SA. Does entitlement card ensure utilization of urban primary healthcare Clinic in Bangladesh? J Matern Child Health. 2020;5(2):213-25

21. Sidze EM, Mutua MK, Donfouet HP. Towards achieving equity in utilisation of maternal health Services in Selected sub-Saharan African Countries: Progress and remaining challenges in priority countries. In: Women and sustainable human development. Cham: Palgrave Macmillan; 2020. p. 111-24. 
22. Mekbib T, Leatherman S. Quality improvement in maternal, neonatal and child health services in sub-Saharan Africa: a look at five resource-poor countries. Ethiop J Health Dev. 2020;34(1).

23. Aseweh Abor P, Abekah-Nkrumah G, Sakyi K, Adjasi C, Abor J. The socioeconomic determinants of maternal health care utilization in Ghana. Int J Soc Econ. 2011;38(7):628-48. https://doi.org/10.1108/03068291111139258.

24. Masters SH, Burstein R, Amofah G, Abaogye P, Kumar S, Hanlon M. Travel time to maternity care and its effect on utilization in rural Ghana: a multilevel analysis. Soc Sci Med. 2013;93:147-54.

25. Alhassan RK, Spieker N, van Ostenberg P, Ogink A, Nketiah-Amponsah E, de Wit TFR. Association between health worker motivation and healthcare quality efforts in Ghana. Hum Resour Health. 2013;11(1):37.

26. Atuoye KN, Dixon J, Rishworth A, Galaa SZ, Boamah SA, Luginaah I. Can she make it? Transportation barriers to accessing maternal and child health care services in rural Ghana. BMC Health Serv Res. 2015;15(1):333.

27. Alhassan RK, Duku SO, Janssens W, Nketiah-Amponsah E, Spieker N, van Ostenberg P, Rinke de Wit TF. Comparison of perceived and technical healthcare quality in primary health facilities: implications for a sustainable National Health Insurance Scheme in Ghana. PloS one. 2015;10(10): e0140109.

28. Alhassan RK, Nketiah-Amponsah E, Ayanore MA, Afaya A, Salia SM, Milipaak J, et al. Impact of a bottom-up community engagement intervention on maternal and child health services utilization in Ghana: a cluster randomised trial. BMC Public Health. 2019;19(1):791.

29. Dotse-Gborgbortsi W, Dwomoh D, Alegana V, Hill A, Tatem AJ, Wright J. The influence of distance and quality on utilisation of birthing services at health facilities in Eastern Region, Ghana. BMJ global health. 2020;4(Suppl 5).

30. Costa JC, Weber AM, Darmstadt GL, Abdalla S, Victora CG. Religious affiliation and immunization coverage in 15 countries in sub-Saharan Africa. Vaccine. 2020;38(5):1160-9.

31. Galaa SZ, Daare K. Understanding barriers to maternal child health services utilisation in northern Ghana. J Soc Dev Afr. 2008;23(2).

32. Alhassan RK, Nketiah-Amponsah E, Arhinful DK. A review of the National Health Insurance Scheme in Ghana: what are the sustainability threats and prospects?. Plos one. 2016;11(11):e0165151.

33. Nketiah-Amponsah E, Alhassan RK, Ampaw S, Abuosi A. Subscribers' perception of quality of services provided by Ghana's National Health Insurance Schemewhat are the correlates? BMC Health Serv Res. 2019;19(1):196.

34. Ravit M, Ravalihasy A, Audibert M, Ridde V, Bonnet E, Raffalli B, et al. The impact of the obstetrical risk insurance scheme in Mauritania on maternal healthcare utilization: a propensity score matching analysis. Health Policy Plan. 2020;35(4):388-98.

35. Agbanyo R. Ghana's national health insurance, free maternal healthcare and facility-based delivery services. Afr Dev Rev. 2020;32(1):27-41.

36. Amissah J, Nakua EK, Badu E, Amissah AB, Lariba L. In search of universal health coverage: the hidden cost of family planning to women in Ghana. BMC research notes. 2020;13(1):58.

37. Dennis ML, Benova L, Goodman C, Barasa E, Abuya T, Campbell OM. Examining user fee reductions in public primary healthcare facilities in Kenya, 1997-2012: effects on the use and content of antenatal care. Int J Equity Health. 2020;19(1):1-13.

38. World Health Organization (WHO). Working together for Health: World Health Report. Geneva: World Health Organization; 2006.

39. Dadzie, D. O. R. C. A. S. (2019). Factors influencing immunization coverage in the Ledzokuku-Krowor municipality-Greater Accra region (Doctoral dissertation, University of Ghana).

40. Rahman MH, Cox AB, Mills SL. A missed opportunity: birth registration coverage is lagging behind Bacillus Calmette-Guérin (BCG) immunization coverage and maternal health services utilization in low-and lower middleincome countries. J Health Popul Nutr. 2019;38(1):25.

41. Ministry of Health $(\mathrm{MoH}) / \mathrm{Ghana}$ Health Service (GHS). Facts and figures. Accra Ghana: Ministry of Health (MoH); 2019.

42. Sheff MC, Bawah AA, Asuming PO, Kyei P, Kushitor M, Phillips JF, Kachur SP. Evaluating health service coverage in Ghana's Volta region using a modified Tanahashi model. Glob Health Action. 2020;13(1):1732664.

\section{Publisher's Note}

Springer Nature remains neutral with regard to jurisdictional claims in published maps and institutional affiliations.

Ready to submit your research? Choose BMC and benefit from:

- fast, convenient online submission

- thorough peer review by experienced researchers in your field

- rapid publication on acceptance

- support for research data, including large and complex data types

- gold Open Access which fosters wider collaboration and increased citations

- maximum visibility for your research: over $100 \mathrm{M}$ website views per year

At BMC, research is always in progress.

Learn more biomedcentral.com/submissions 